\title{
Validação de um vídeo educativo para promoção do apego entre mãe soropositiva para HIV e seu filho
}

Validation of an educational video for the promotion of attachment between seropositive HIV mother and his child

Validación de un video educativo para la promoción del apego entre madre seropositiva para HIV y su hijo

\author{
Régia Moura Barbosa', Ana Karina Bezerra" \\ 'Maternidade Escola Assis Chateaubriand. Fortaleza, CE \\ "Universidade Federal do Ceará. Departamento de Enfermagem. Fortaleza, CE
}

Submissão: 20/01/2010

Aprovação: 20/11/2010

\section{RESUMO}

O objetivo da pesQuisa foi construir um vídeo educativo para promoção do apego entre mãe HIV positiva e seu filho. Tratou-se de um ensaio clínico randomizado. As fases do estudo foram constituídas por desenvolvimento de um roteiro, avaliação, gravação e edição do vídeo, coleta de dados, filmagem do binômio e validação. O roteiro foi avaliado por especialistas técnicos e de conteúdo. Participaram 24 gestantes HIV positivas atendidas no período (Grupo Controle=12 e Grupo Experimental=12). O vídeo foi validado com um protocolo de observação da interação mãe-bebê. As mães do grupo intervenção obtiveram resultados mais favoráveis do Que o controle, mostrando a eficácia do vídeo.

Descritores: Puerpério; HIV; Educação em Saúde.

\section{ABSTRACT}

The objective of this research was to build an educational video to promote the attachment of HIV-positive mother and her child. That was a randomized clinical trial. The phases of the study was constituted by the developedment of the script, followed by the assessment, recording and editing of video, data collection, and validation and filming of the binomial. The roadmap has been assessed by technical experts and content. Data collection occurred between May and October 2008. 24 women attending HIV in the period, 12 of the control group and 12 in the intervention group took part of the study. We validated the video with the Protocol for Observation of mother-infant interaction. The mothers in the intervention group obtained more favorable results than the control one, showing the effectiveness of the video.

Key words: Puerperium; HIV, Education, Health

\section{RESUMEN}

El objetivo de esta investigación fue la creación, evaluación y validación de un vídeo educativo para promover el adjunto de madres seropositivas para el $\mathrm{VIH}$ y sus hijos. Estudio metodológico, del tipo ensayo clínico aleatorizado. Primero, fue desarrollado el guión, y seguimos por la evaluación, produción de la pelicula y edición del vídeo, la recogida de datos, la validación y la filmación del binomio. El guión ha sido evaluado por expertos técnicos y de contenido. La recopilación de datos ocurrió entre mayo y octubre de 2008. Participaron, 24 mujeres seropositivas para el HIV Que fueron atendidas en el periodo. 12 participaron del grupo control y 12, del grupo de intervención. Validamos el vídeo con el Protocolo para la Observación de la interacción madre-hijo. Madres en el grupo de intervención obtuvo resultados más favorables que los de control, demostrando la eficacia del vídeo.

Descriptores: Periodo de posparto; VIH; Educación em salud. 


\section{INTRODUÇÃO}

O apego é um mecanismo básico dos seres humanos e um comportamento biologicamente programado. O papel do apego na vida dos seres humanos envolve o conhecimento de que uma figura de apego disponível vai oferecer respostas, proporcionando um sentimento de segurança Que é fortificador da relação $0^{(1)}$.

Para a mãe soropositiva, o apego pode estar prejudicado, isso por Que ela lida com Questões delicadas como o não amamentar, o isolamento, somando-se a discriminação e o estigma Que sofre por si mesma, pelos familiares, e às vezes pela equipe de saúde Que presta cuidados.

Essas mulheres carregam consigo o medo, a insegurança e a dúvida, muitas vezes sem entender direito o que acontece. Vivenciam sentimentos de incerteza e culpa de, possivelmente, terem infectados seus filhos.

O medo da morte representa o maior conflito vivido por essas mulheres. Estar com AIDS parece ser incompatível com o ser mãe. A AIDS simboliza a morte e o papel social de mãe é cuidar do filho, logo, muitas vezes, ela acredita Que não cumprirá seu papel, Quebrando assim o contrato social.

Outro fator importante para a diminuição do apego é o fato dessas mulheres não poder amamentar, acreditando não serem capazes de obter um apego seguro com o seu filho, dificultando o estabelecimento do vínculo entre ambos.

As vantagens do aleitamento materno para o recém-nascido estão vinculadas ao fato de este suprir as necessidades nutricionais da criança por aproximadamente os seis primeiros meses de vida, oferecendo resistência contra infecções e estabelecendo vínculo psicológico mãe e filho ${ }^{(2)}$.

A amamentação dos recém-nascidos por mães portadoras do vírus HIV será sempre contra-indicada, tenham ou não recebido antitoxinas. O aleitamento materno deixa de ser vantajoso e passa a representar riscos reais para o bebê. Por isso, as mães devem ser aconselhadas à supressão da lactação e à substituição por outros leites. É relevante Que a puérpera, durante sua permanência na maternidade, receba suporte por parte da equipe de enfermagem para não amamentar sem se sentir discriminada ${ }^{(3)}$.

Essas mulheres precisam de uma assistência Que garanta meios de enfrentamento para tal problemática. Elas precisam ser orientadas Quanto ao preparo; à oferta do leite; aos cuidados Que ela deverá ter com suas mamas para prevenir complicações. Necessitará, também, de um apoio direcionado a estar mais próxima de seu filho, contribuindo para o desenvolvimento de sua sensibilidade enQuanto mãe, garantindo a relação de apego com seu filho, independente da amamentação.

Existem outras formas de estimular o apego. Os gestos carinhosos, a fala, o toque, olhar o bebê, mostrar objetos e cantar são alguns exemplos favoráveis a este estímulo ${ }^{(4)}$.

Em um estudo sobre as interações adversas da mãe soropositiva e o desenvolvimento precoce de seus bebês, a sensibilidade materna mostrou-se prejudicada, pelo fato de essas mulheres não poderem amamentar, despertando na mãe, sentimentos contraditórios ao apego, como a culpa e a tristeza. Como resultados, o estudo mostrou, Que as reações desfavoráveis à interação com seus bebês, dificulta o estabelecimento de um apego seguro ${ }^{(5)}$.

Tendo em vista a influência da AIDS na promoção do apego entre mãe soropositiva e seu filho, ficamos motivadas a realização deste estudo como uma proposta inovadora. Assim, construímos um vídeo educativo para Que o apego entre a mãe soropositiva para o HIV e seu filho seja eficaz e seguro.

Acreditamos Que a utilização dessa estratégia educativa, os enfermeiros irão contribuir para promoção do apego entre o binômio (mãe soropositiva para o HIV e seu filho), bem como humanizar o cuidado prestado a essa clientela específica, diminuindo os riscos Que a falta do apego pode ocasionar. Podendo mãe e bebê desfrutar de uma relação recíproca e desejante, com um relacionamento afetivo e eficaz.

\section{MÉTODO}

O estudo foi metodológico, do tipo ensaio clínico randomizado. O estudo metodológico refere-se às investigações dos métodos de obtenção, organização e análise de dados, tratando da elaboração, validação e avaliação dos instrumentos e técnicas de pesQuisa. Sua meta é a elaboração de um instrumento confiável, preciso e utilizável que possa ser empregado por outros pesquisadores $^{(6)}$.

O estudo foi desenvolvido em um hospital público municipal, referência em obstetrícia, no Estado do Ceará. A escolha da instituição pesquisada se deu por suas características: presta atendimento à gestante de alto risco; é referência para atendimento de gestantes oriundas da capital e do interior do Estado; constitui campo de prática e de ensino das diferentes áreas da saúde e faz parte do elenco das maternidades de referência do Estado para pacientes soropositivas. O período da coleta de dados ocorreu entre maio e outubro de 2008.

A primeira etapa do estudo foi o da elaboração do roteiro. Para isso, pesquisaram-se na literatura os assuntos acerca da interação mãe e bebê; Apego; Cuidados com a criança exposta ao vírus HIV e atividades estimuladoras do apego.

Após a primeira versão do roteiro, houve a submissão à análise dos juízes da área de enfermagem (conteúdo) e comunicação (técnica). As sugestões foram analisadas e acatadas, estabelecendo a versão final do roteiro.

Os aspectos avaliados pelos juízes de conteúdo foram: o objetivo do vídeo; conteúdo; relevância e ambiente. Os juízes da área técnica avaliaram: funcionalidade, usabilidade e eficiência ${ }^{(7)}$.

A gravação e edição do vídeo foram realizadas no Lab-Com Saúde e contou-se com o apoio de um técnico da área de criação de vídeo educativo.

Após a finalização do vídeo, ocorreu a transmissão deste para às mulheres do grupo de intervenção.

Após 48 horas de pós-parto se deu a etapa de avaliação da interação mãe e bebê, momento em Que todos os binômios independentes de eual grupo fizessem parte seriam filmados, como o intuito de observar os comportamentos de apego da mãe, e assim, avaliar a eficácia do vídeo.

Para avaliação da interação entre mãe e bebê, contou-se com o apoio de três acadêmicas de enfermagem, previamente treinadas.

Nessa etapa, adotou-se o Protocolo de Observação da Interação Mãe-Bebê de 0 a 6 meses, por ser o único protocolo Que possibilita a avaliação da interação mãe e bebê a partir do nascimento $^{(8)}$. 
Este protocolo é um exemplo de análise da interação por meio do método de observação direta e registro do comportamento em forma de escala. Contém $2 \mathrm{I}$ itens, sendo 12 referentes ao comportamento da mãe e 8 ao comportamento do bebê durante a interação, bem como 01 item referente ao comportamento da díade (sintonia da interação). Para o presente estudo foram adotados apenas os itens propostos para avaliação do comportamento materno.

A população das mulheres participantes do estudo foi constituída por todas as gestantes soropositivas para o HIV atendidas no período da coleta de dados, totalizando 27. Participaram do estudo 24 mulheres gestantes, soropositivas para o HIV, independentemente da idade, cor e religião, Que realizaram o pré-natal e o parto na instituição escolhida para desenvolvimento do estudo. Três não puderam participar da pesQuisa: uma por motivo de aborto; as outras duas por desistir de participar da fase da validação do vídeo, pois referiram estarem constrangidas com o fato de serem filmadas.

Estabeleceram-se como critérios de inclusão das participantes: ser soropositiva para o HIV, ter tido seu filho no período da coleta de dados, estarem no terceiro trimestre da gravidez e aceitarem participar de todas as etapas da pesquisa.

Definiram-se os seguintes critérios de exclusão: estar com o estado de saúde comprometido, impossibilitando o término do estudo; ser portadora de aids; ser transferida para outro hospital; não ter feito pré-natal ou parto no estabelecimento escolhido para o desenvolvimento do estudo.

O pré-natal para as gestantes soropositivas para o HIV na instituição escolhida ocorre nas segundas-feiras, no período da tarde. Dessa forma, procedeu-se a uma alternância: uma semana era destinada ao Grupo de Intervenção; a outra, ao Grupo Controle, estabelecendo a randomização do estudo.

Para as participantes do Grupo de Intervenção e Controle, aplicou-se um formulário contendo perguntas sobre o perfil socioeconômico, história sexual e reprodutiva, diagnóstico e tratamento para o HIV. A exibição do vídeo foi somente para as mulheres pertencentes ao Grupo de Intervenção.

A avaliação da interação entre mãe e bebê foi realizada nos dois grupos, no período de puerpério imediato.

Os dados foram compilados e analisados utilizando um programa estatístico Kolmogorov-Smirnov $p<0,05$ e posteriormente organizados em tabelas.

O projeto de pesquisa foi aprovado com o número do protocolo 2 I/08 pelo Comitê de Ética e Pesquisa da Universidade Federal do Ceará, obedecendo a Resolução 196/1996 ${ }^{(9)}$.

Foi solicitada previamente a liberação da instituição em Que o estudo foi realizado, explicando a importância do trabalho para a população específica.

As mulheres de ambos os grupos, ou seja, controle e de intervenção foram convidadas a participar da pesquisa no dia de seu pré-natal, momento em Que os objetivos foram explicados e caso a participante aceitasse participar do estudo, assinavam um termo de consentimento em duas cópias, ficando uma com ela. Ressalta-se Que os princípios éticos da pesquisa foram explicados para as participantes.

\section{RESULTADOS}

Como mostrado na Tabela 1, a faixa etária das gestantes variou de 19 a 44 anos, predominando mulheres adultas jovens: I I $(45,9 \%)$ gestantes tinham entre 19 e 24 anos.

Com relação à situação conjugal, nenhuma gestante era casada, sendo Que 17(70,8\%) viviam em união consensual, I (4,2\%) estava viúva há três meses e 6(25\%) eram solteiras.

Quanto à renda familiar mensal, identificou-se a metade das gestantes possuíam renda menor Que um salário mínimo, o Que torna mais evidente a interdependência entre AIDS e pobreza.

O grau de escolaridade variou de 01 a 16 anos de estudo. 14 $(58,3 \%)$ perfizeram o ensino fundamental completo.

Quanto aos aspectos da vida sexual e reprodutiva das participantes, a Tabela 2 mostra Que mais de 50\% das mulheres faziam

Tabela 1. Características sócio-demográficas das participantes do estudo. Fortaleza, 2008.

\begin{tabular}{|c|c|c|}
\hline Características sócio-demográficas & $\mathrm{n}$ & $\%$ \\
\hline \multicolumn{3}{|l|}{ Faixa Etária } \\
\hline $19-24$ anos & 11 & 45,9 \\
\hline $25-30$ anos & 8 & 33,2 \\
\hline $31-44$ anos & 5 & 20,9 \\
\hline \multicolumn{3}{|l|}{ Estado Civil } \\
\hline Solteira & 6 & 25 \\
\hline Viúva & 1 & 4,2 \\
\hline União Consensual & 17 & 70,8 \\
\hline \multicolumn{3}{|l|}{ Renda $(n=24)$} \\
\hline Menos de I salário mínimo & 12 & 50 \\
\hline Entre 1 e 2 salários mínimos & 8 & 33,3 \\
\hline Mais de 2 a 3 salários mínimos & 2 & 8,3 \\
\hline Mais de 3 salários & 1 & 4,2 \\
\hline Não sabe & 1 & 4,2 \\
\hline \multicolumn{3}{|l|}{ Escolaridade $(n=24)$} \\
\hline De 1 a 4 anos & 4 & 16,7 \\
\hline Mais de 4 a 8 anos & 14 & 58,3 \\
\hline Mais de 8 a 12 anos & 5 & 20,8 \\
\hline Mais de 12 anos & 1 & 4,2 \\
\hline
\end{tabular}

Tabela 2. História sexual e reprodutiva das participantes do estudo. Fortaleza, 2008.

\begin{tabular}{lcc}
\hline História Sexual e Reprodutiva & $\mathbf{n}$ & $\%$ \\
\hline $\begin{array}{l}\text { Uso regular do condom nas relações } \\
\text { sexuais }\end{array}$ & & \\
$\quad$ Não & 10 & 41,7 \\
$\quad$ Sim & 14 & 58,3 \\
Parceiro Fixo & & \\
$\quad$ Não & 2 & 8,3 \\
$\quad$ Sim & 22 & 91,7 \\
História de outras DST & & \\
$\quad$ Não & 20 & 83,3 \\
$\quad$ Sim & 4 & 16,7 \\
Prevenção ginecológica & & \\
$\quad$ Não & 2 & 8,3 \\
$\quad$ Sim & 22 & 91,7 \\
Gravidez planejada & & \\
$\quad$ Não & 18 & 75,0 \\
$\quad$ Sim & 6 & 25,0 \\
Desejo de engravidar mesmo sabendo & & \\
do diagnóstico & & \\
$\quad$ Não & 22 & 91,7 \\
$\quad$ Sim & 2 & 8,3 \\
\hline
\end{tabular}


uso regular do preservativo. Todas afirmaram ter contraído o vírus HIV mediante relações heterossexuais, $22(91,7 \%)$ foram contaminadas por parceiros fixos e $2(8,3 \%)$ não tinham parceiro fixo.

No Que toca à história de outras DST, $20(83,3 \%)$ participantes relataram não ter história de DST, e 4(16,7\%) tinham diagnósticos de sífilis e HPV.

A maioria das gestantes $22(91,7 \%)$ afirmaram submeter-se ao exame de papanicolau regularmente, $18(70 \%)$ não haviam planejado a gravidez, contrapondo-se a 6(25\%) Que Quiseram. Dessas, $2(8,3 \%)$ desejaram engravidar mesmo sabendo da soropositividade.

A Tabela 3 demonstra a comparação dos comportamentos de envolvimento entre mãe e filho nos dois grupos (comparação e intervenção). Os itens avaliados foram os preconizados pelo Protocolo de Observação da Interação entre Mãe e Bebê $\hat{e}^{(13)}$. A comunicação verbal apresentou pontuação igual no Que se refere ao conceito "Moderado", 4(33,3\%) mães, independentemente de assistirem ao vídeo, foram avaliadas como mantendo uma comunicação rápida com a criança, interagindo verbalmente por pouco tempo.

Quanto ao contato visual, as participantes dos dois grupos tiveram conceitos "Moderados" ou "Muito", porém com um Quantitativo diferente. No Grupo Controle, houve 2(16,7\%) mães Que mantiveram o contato visual considerado "Muito", contrapondose ao Grupo de Intervenção com 1 1 $(91,7 \%)$ mães Que mantinham o mesmo contato, considerado "Muito".

No Grupo Controle, apenas uma mãe apresentou "Pouca" atenção ao seu filho, enQuanto 1 I $(91,7 \%)$ mães apresentaram atenção "Moderada". Sete mães do Grupo de Intervenção tiveram "Muita" atenção e cinco "Sempre" estiveram atentas às crianças.

A Quantidade de afetos positivos foi mais satisfatória nas mães do Grupo de Intervenção 07 (58,3\%), Que apresentaram esse comportamento com "Muita" frequência e 07 (58,3\%) mães do Grupo Controle apresentaram de forma "Moderada".

Na Tabela 4, mostra os resultados obtidos nos Grupos Controle e Intervenção, Quanto aos comportamentos de sensitividade, ou seja, o envolvimento da mãe com o seu bebê.

Neste estudo, 7(58,3\%) mães do Grupo de Intervenção "Sem-

Tabela 3. Comparação dos comportamentos de envolvimento entre o grupo controle e intervenção. Fortaleza, 2008.

\begin{tabular}{|c|c|c|c|c|c|c|c|c|c|c|c|c|c|}
\hline \multirow{2}{*}{ Ações } & \multicolumn{2}{|c|}{ Nenhuma } & \multicolumn{2}{|c|}{ Pouca } & \multicolumn{2}{|c|}{ Moderada } & \multicolumn{2}{|c|}{ Muita } & \multicolumn{2}{|c|}{ Sempre } & \multicolumn{2}{|c|}{ Não aplicável } & \multirow{2}{*}{$\begin{array}{c}\text { Testes } \\
\text { estatísticos }\end{array}$} \\
\hline & $\mathrm{n}$ & $\%$ & $\mathrm{n}$ & $\%$ & $\mathrm{n}$ & $\%$ & $\mathrm{n}$ & $\%$ & $\mathrm{n}$ & $\%$ & $\mathrm{n}$ & $\%$ & \\
\hline Comunicação verbal & & & & & & & & & & & & & $K S=1,255$ \\
\hline GC & 4 & 33,3 & 4 & 33,3 & 4 & 33,3 & - & 0,0 & - & 0,0 & - & 0,0 & $D P=0,85-0,16$ \\
\hline GI & 1 & 8,3 & I & 8,3 & 4 & 33,3 & 4 & 33,3 & 2 & 41,7 & - & 0,0 & $P=0,100$ \\
\hline Contato visual & & & & & & & & & & & & & $K S=1,837$ \\
\hline GC & - & 0,0 & - & 0,0 & 10 & 83,3 & 2 & 16,7 & - & 0,0 & - & 0,0 & $D P=0,38-0,66$ \\
\hline Gl & - & 0,0 & - & 0,0 & 1 & 8,3 & 11 & 91,7 & - & 0,0 & - & 0,0 & $P=0,002$ \\
\hline Afeto positivo & & & & & & & & & & & & & $K S=2,449$ \\
\hline GC & - & 0,0 & 5 & 41,7 & 7 & 58,3 & - & 0,0 & - & 0,0 & - & 0,0 & $D P=0,51-0,51$ \\
\hline Gl & - & 0,0 & - & 0,0 & - & 0,0 & 7 & 58,3 & 5 & 41,7 & - & 0,0 & $P=0,000$ \\
\hline $\begin{array}{l}\text { Atenção da mãe com } \\
\text { o bebê }\end{array}$ & & & & & & & & & & & & & $K S=2,449$ \\
\hline GC & - & 0,0 & I & 8,3 & 11 & 91,7 & - & 0,0 & - & 0,0 & - & 0,0 & $D P=0,28-0,51$ \\
\hline GI & - & 0,0 & - & 0,0 & - & 0,0 & 7 & 58,3 & 5 & 41,7 & - & 0,0 & $P=0,000$ \\
\hline
\end{tabular}

Tabela 4. Comparação dos comportamentos de sensitividade entre o grupo controle de intervenção. Fortaleza, 2008.

\begin{tabular}{|c|c|c|c|c|c|c|c|c|c|c|c|c|c|}
\hline \multirow{2}{*}{ Ações } & \multicolumn{2}{|c|}{ Nenhuma } & \multicolumn{2}{|c|}{ Pouca } & \multicolumn{2}{|c|}{ Moderada } & \multicolumn{2}{|c|}{ Muita } & \multicolumn{2}{|c|}{ Sempre } & \multicolumn{2}{|c|}{ Não aplicável } & \multirow{2}{*}{$\begin{array}{c}\text { Testes } \\
\text { estatísticos }\end{array}$} \\
\hline & $\mathrm{n}$ & $\%$ & $\mathrm{n}$ & $\%$ & $\mathrm{n}$ & $\%$ & $\mathrm{n}$ & $\%$ & $\mathrm{n}$ & $\%$ & $\mathrm{n}$ & $\%$ & \\
\hline Contato corporal & & & & & & & & & & & & & $K S=1,630$ \\
\hline GC & - & 0,0 & - & 0,0 & 10 & 83,3 & 2 & 16,7 & - & 0,0 & - & 0,0 & $D P=0,45-0,67$ \\
\hline GI & - & 0,0 & - & 0,0 & 1 & 8,3 & 4 & 33,3 & 7 & 58,3 & - & 0,0 & $P=0,010$ \\
\hline Consolar o bebê & & & & & & & & & & & & & $K S=I, 4 I 4$ \\
\hline GC & - & 0,0 & - & 0,0 & 3 & 25,0 & - & 0,0 & - & 0,0 & 9 & 75,0 & $D P=0,00-0,040$ \\
\hline GI & - & 0,0 & - & 0,0 & - & 0,0 & I & 8,3 & 5 & 41,7 & 6 & 50,0 & $P=0,037$ \\
\hline Reação ao choro & & & & & & & & & & & & & $K S=I, 4 I 4$ \\
\hline GC & - & 0,0 & - & 0,0 & 3 & 25,0 & - & 0,0 & - & 0,0 & 9 & 75,0 & $D P=0,00-0,51$ \\
\hline GI & - & 0,0 & - & 0,0 & - & 0,0 & 2 & 16,7 & 4 & 33,3 & 6 & 50,0 & $P=0,037$ \\
\hline \multicolumn{14}{|l|}{ Reação ao } \\
\hline $\begin{array}{l}\text { comportamento do } \\
\text { bebê }\end{array}$ & - & 0,0 & - & 0,0 & 12 & 100,0 & - & 0,0 & - & 0,0 & - & 0,0 & $\begin{array}{c}K S=2,449 \\
D P=0,00-0,49\end{array}$ \\
\hline GC & - & 0,0 & - & 0,0 & - & 0,0 & 8 & 66,7 & 4 & 33,3 & - & 0,0 & $P=0,000$ \\
\hline \multicolumn{14}{|l|}{ Gl } \\
\hline $\begin{array}{l}\text { Intensidade da } \\
\text { resposta }(+)\end{array}$ & & & & & & & & & & & & & $K S=1,837$ \\
\hline GC & 1 & 8,3 & 1 & 8,3 & 10 & 83,3 & - & 0,0 & - & 0,0 & - & 0,0 & $\begin{array}{c}D P=0,67-0,73 \\
P=0,2\end{array}$ \\
\hline Gl & - & 0,0 & - & 0,0 & - & 0,0 & 6 & 50,0 & 3 & 25,0 & - & 0,0 & \\
\hline Sensitividade & & & & & & & & & & & & & \\
\hline GC & - & 0,0 & 1 & 8,3 & 8 & 66,7 & 3 & 25,0 & - & 0,0 & - & 0,0 & $\begin{array}{l}K J=1,03 / \\
D=057-051\end{array}$ \\
\hline GI & - & 0,0 & - & 0,0 & - & 0,0 & 7 & 58,3 & 5 & 41,7 & - & 0,0 & $\begin{array}{c}D P=0,3 /-0,31 \\
P=0,002\end{array}$ \\
\hline
\end{tabular}


Tabela 5. Comparação das ações negativas das mães do Grupo Controle e de Intervenção. Fortaleza, 2008.

\begin{tabular}{|c|c|c|c|c|c|c|c|c|c|c|c|c|c|}
\hline \multirow{2}{*}{ Ações } & \multicolumn{2}{|c|}{ Sempre } & \multicolumn{2}{|c|}{ Muito } & \multicolumn{2}{|c|}{ Moderada } & \multicolumn{2}{|c|}{ Pouco } & \multicolumn{2}{|c|}{ Nunca } & \multicolumn{2}{|c|}{ Não aplicável } & \multirow{2}{*}{$\begin{array}{c}\text { Testes } \\
\text { estatísticos }\end{array}$} \\
\hline & $n$ & $\%$ & $\mathrm{n}$ & $\%$ & $\mathrm{n}$ & $\%$ & $\mathrm{n}$ & $\%$ & $n$ & $\%$ & $n$ & $\%$ & \\
\hline Afeto negativo & & & & & & & & & & & & & $K S=0,204$ \\
\hline GC & - & 0,0 & - & 0,0 & - & 0,0 & I & 8,3 & II & 91,7 & - & 0,0 & $D P=0,28-0,00$ \\
\hline GI & - & 0,0 & - & 0,0 & - & 0,0 & - & 0,0 & 12 & 100,0 & - & 0,0 & $P=0,000$ \\
\hline Intrusividade & & & & & & & & & & & & & $K S=0,000$ \\
\hline GC & - & 0,0 & - & 0,0 & - & 0,0 & - & 0,0 & 12 & 100,0 & - & 0,0 & $D P=0,00-0,000$ \\
\hline GI & - & 0,0 & - & 0,0 & - & 0,0 & - & 0,0 & 12 & 100,0 & - & 0,0 & $P=0,000$ \\
\hline
\end{tabular}

pre" mantiveram contato corporal com seus bebês, seguidas de 4(33,3\%) mães Que mantinham "Muito" contato, e I (8,3\%) com contato "Moderado". No Grupo Controle, em 10(83,3\%) mães predominou o contato "Moderado".

Os tipos de contato variaram desde o simples fato de tocar na criança, segurá-la para realizar massagens e aconchegá-las.

A eficiência em consolar o bebê foi avaliada apenas na presença do choro. Assim, 9(75,0\%) das mães do Grupo Controle e 6(50,0\%) do Grupo de Intervenção não puderam ser avaliadas.

Das mães do Grupo Controle Que consolaram seus bebês, $3(25 \%)$ tiveram conceito "Moderado", e as do Grupo de Intervenção, I $(8,3 \%)$ e $5(41,7 \%)$ obtiveram conceitos "Muito" e "Sempre", respectivamente.

Quanto a "reação ao choro da criança", ainda na Tabela 4, o ato de intervenção da mãe com a criança para parar de chorar, mostra Que $4(33,3 \%)$, das mães do grupo de intervenção reagiram "Sempre" ao choro do bebê.

$\mathrm{Na}$ avaliação da sensitividade, no Grupo de Intervenção, mais da metade, $7(58,3 \%)$, das participantes apresentaram "Muita" sensitividade, no Grupo Controle apenas 3(25,0\%).

Os dados apontaram uma diferença estatisticamente significativa entre os dois grupos para o comportamento "Intensidade da resposta positiva". No Grupo Controle 10(83,3\%) mães responderam com intensidade "Moderada" e 6(50\%) do Grupo de Intervenção responderam "Sempre".

Por último, na Tabela 5, observam-se os resultados obtidos nos dois grupos Intervenção e Controle, Quanto aos comportamentos afeto negativo e Intrusividade.

Os comportamentos apresentados na Tabela 5 apresentam pontuação inversa dos comportamentos, o escore (5) passa a receber conceito "Nunca", apresentando aspecto positivo na avaliação, e o (1) "Sempre", interpretado como atitude negativa na avaliação desses comportamentos.

\section{DISCUSSÃO}

Em um estudo epidemiológico sobre a notificação compulsória de gestantes HIV positivas e crianças expostas em Porto Alegre entre os anos de 2002 e 2005, foi constatado Que 79,3\% das gestantes soropositivas estavam na faixa etária de 20 a 35 anos ${ }^{\left({ }^{(10)}\right.}$. Embora preocupante, os dados encontrados são esperados, pois esta é a faixa etária de maior freeüência reprodutiva.

Em relação à situação conjugal das gestantes soropositivas para o HIV, a maioria das participantes do estudo $17(70,8 \%)$ viviam em união consensual com o parceiro e nenhuma era casada. Fato que contraria a tendência verificada nos últimos anos, em Que há um aumento no número de casamentos realizados no Brasil, em parte devido à legalização das uniões consensuais(11).

Quanto à renda familiar mensal, identificou-se a metade das gestantes possuindo uma renda familiar menor Que um salário mínimo. Assim, o Plano de Feminização da AIDS define metas para o fortalecimento da mulher Que se encontra em situação de pobre$\mathrm{za}^{(12)}$. No Brasil, Quase um terço da população, 49 milhões de pessoas vivem com até meio salário mínimo ${ }^{(1)}$.

A baixa escolaridade também ajuda na disseminação do vírus. A variável escolaridade tem sido utilizada como marcador da situação sócio-econômica, e o aumento na proporção de casos de AIDS nos indivíduos com menor escolaridade tem sido denominado pauperização do agravo ${ }^{(13)}$. Nesse estudo a média foi de 7,5 anos de estudo, predominando o ensino fundamental completo, perfazendo mais de $50 \%$ da amostra estudada.

A dificuldade em negociação do uso do preservativo reafirma a vulnerabilidade feminina frente à $\operatorname{AIDS}^{(12)}$. Nesse estudo, $14(58,3 \%)$ participantes faziam uso regular, e $10(41,7 \%)$ usavam esporadicamente a camisinha.

Atualmente no Brasil, a principal via de transmissão é a relação heterossexual desprotegida, respondendo por $86,8 \%$ dos casos notificados em mulheres e por $25,75 \%$ em homens ${ }^{(14)}$. Nesse estudo todas as participantes $24(100 \%)$ do estudo afirmaram ter contraído o vírus HIV mediante relações heterossexuais e mais de $50 \%$ do parceiro fixo.

Diferentes pesquisadores referem Que práticas de prevenção não fazem parte da vida da grande maioria das mulheres com parceiro fixo. A explicação se prende ao fato de elas serem, majoritariamente, pobres, desinformadas e sem poder de barganha - o Que, de alguma forma, aproxima o conceito da "Feminização, interiorização e pauperização" da AIDS entre as mulheres ${ }^{(12-14)}$.

Assim, além da AIDS as mulheres ficam vulneráveis a outras DST. Neste estudo 4 (16,7\%) apresentaram sífilis e/ou Papiloma Vírus Humano - HPV.

Esses resultados corroboram com outros para detectar a prevalência da infecção pelo HPV em mulheres soropositivas e soronegativas para o HIV, os estudos mostram Que a mulher portadora do vírus HIV tem uma maior prevalência. Havendo ainda predominância da associação de vários tipos de HPV, principalmente os tipos 6,11 e 16, levando a uma maior patogenicidade por parte da infecção ${ }^{(15-17)}$. Neste estudo $22(91,7 \%)$ mulheres realizavam do exame de prevenção do câncer de colo uterino.

Sobre o planejamento da gravidez, os dados encontrados reafirmam Que as mulheres não estão tendo suas gestações planejadas. Este fato está relacionado, principalmente a não utilização de métodos contraceptivos e ao uso incorreto destes. Dezoito participantes não planejaram a gravidez.

Nesse universo, um dado importante é Que duas participantes 
expressaram o desejo de engravidarem mesmo sabendo da soropositividade para o HIV.

Apesar de haver poucos trabalhos Que enfocam a experiência de mães portadoras do HIV/AIDS, alguns estudos brasileiros têm indicado Que a maternidade permanece numa posição idealizada para as gestantes, sendo colocada acima da infecção ${ }^{(18-19)}$. Essas mulheres precisam de melhores informações acerca da prevenção da transmissão vertical, bem como dos aspectos relevantes da maternidade, como o apego.

Os comportamentos Que compõem um dado padrão de apego operam segundo um modelo interno de funcionamento, construído a partir da relação com a figura de apego no início da vida, guiando as relações futuras. $\mathrm{O}$ apego envolve uma relação de cunho afetivo para com a mãe, o Que leva o bebê a procurar a presença e o conforto maternos, particularmente, Quando se sente assustado ou inseguro( ${ }^{(1)}$.

O Protocolo de Avaliação da Interação Mãe e Bebê de 0 a 6 meses dividem a avaliação dos itens maternos em três categorias: envolvimento, sensitividade e intrusividade/aspectos negativos. $\mathrm{O}$ envolvimento materno é pontuado por medidas Quantitativas referentes à comunicação verbal, contato ocular, afeto positivo e atenção geral ao bebêt(8)

$\mathrm{Na}$ avaliação dos binômios participantes deste estudo, todos os itens de envolvimento avaliados tiveram um resultado estatisticamente significante, exceto a comunicação verbal. Isso pode ser justificado pela idade da criança, já Que o apego se estabelece através do estímulo de ambos, mãe e filho.

Os recém-nascidos (até 28 dias) concentram-se em olhar a mãe, fechar os olhos e mamar. lá a interação da mãe com a criança nessa idade se dá, principalmente, por meio do olhar e do toque. Diferentemente de um bebê com maior idade, aproximadamente 10 semanas, com Que a mãe passa a utilizar uma maior variedade de comportamentos, tais como: cantar, falar, sorrir e mostrar objetos ${ }^{(8)}$.

Esses comportamentos são estímulos para o desenvolvimento da criança. Estando a mãe mais próxima, atendendo às necessidades do seu filho, o apego formado entre ambos torna-se seguro, auxiliando no desenvolvimento saudável da criança.

Quanto aos comportamentos de sensitividade, observa-se que todos obtiveram conceitos mais satisfatórios nas mães Que faziam parte do grupo de intervenção.

A sensitividade consiste na habilidade materna em perceber, interpretar e responder às necessidades comunicativas da criança, e assim, adeuire posição central na construção de uma relação de mutualidade, contribuindo para a formação de um apego seguro ${ }^{(1)}$.

A formação e a Qualidade do apego dependem dessa interação. $\mathrm{O}$ apego seguro depende da sensitividade materna, ou seja, da capacidade da mãe em responder às pistas do bebê com sorriso, fala e carinho ${ }^{(20)}$.

Assim, o vídeo para a promoção do apego mostrou-se eficaz na interação entre mãe e bebê Que experienciavam a realidade da infecção para o HIV.

Com a implementação do vídeo educativo de forma contínua e progressiva para as mães soropositivas para o HIV, podemos conseguir o engajamento não só da clientela específica, mas dos profissionais Que trabalham com esse público.

Ao se compararem as ações negativas e de intrusividade das mães soropositivas do Grupo de Intervenção e Controle, conforme se observa na tabela 5, não teve associação estatística para $\mathrm{p}<$ 0,05 . Os dados apontam Que as mães, mesmo vivenciando o conflito da maternidade e a soropositividade para o HIV, não apresentam atitudes negativas para com os seus bebês.

\section{CONSIDERAÇÕES FINAIS}

A mulher continua sendo vítima da infecção, aumentando a estatística dos portadores do HIV. Esta mulher ao ser mãe vivencia juntamente com a infecção do HIV, sentimentos de tristeza, ansiedade e culpa por acharem Que podem ter infectado seus filhos. Estes sentimentos somados aos cuidados impostos ao binômio desde o pré-natal até o pós-parto, tais como os cuidados imediatos com o recém-nascido, acarretando em uma separação brusca entre ambos e o não amamentar leva a deficiência na promoção do apego entre mãe soropositiva para o HIV e seu filho.

O apego é primordial para o desenvolvimento do ser. A mãe soropositiva para o HIV precisa de um suporte Que facilite a promoção do apego. O vídeo é uma excelente estratégia educativa para o aprendizado do apego entre mãe e bebê.

Todos os comportamentos avaliados foram favoráveis ao grupo de intervenção, demonstrando Que o vídeo educativo foi eficaz para a promoção do apego. As mães Que assistiram ao vídeo mantiveram contato corporal com maior frequência, consolaram mais seus filhos, reagiram melhor ao choro, responderam ao comportamento social do bebê, sendo a intensidade desta resposta maior nessas mães. A sensitividade, considerada como comportamento de maior importância para a promoção do apego, foi avaliada como "Muita" e "Sempre", para as mães do grupo de intervenção, contrapondo-se as do grupo controle, em Que a maioria tiveram suas avaliações como "Moderada".

Comportamentos Que não mostraram significância foram o afeto negativo e a intrusividade. Apesar das mães estarem vivenciando um momento difícil em suas vidas, estas independente do vídeo educativo não demonstraram atitudes negativas nem atitudes exageradas com seus filhos.

Concluímos que o vídeo educativo promove o apego seguro entre o binômio Que vivencia a contaminação do HIV. Assim, sugere-se Que a educação a esta clientela seja permanente e Que o vídeo construído e validado possa contribuir com a prática dos profissionais da saúde, promovendo o apego a este binômio.

\section{REFERÊNCIAS}

I. Bowlby. Apego e perda: a natureza do vínculo. São Paulo: Martins Fontes; 200I.

2. Araújo OD. Aleitamento materno: fatores Que levam ao desmame precoce. Rev Bras Enferm 2008; 61 (4): 488-92.
3. Ministério da Saúde (Brasil). Programa Nacional de DST/Aids. Recomendações para profilaxia da transmissão vertical do HIV e terapia anti-retroviral em gestantes. Brasília: Ministério da Saúde; 2006. 
4. Piccinini CA. Diferentes perspectivas na análise da interação pais-bebê/criança. Psicol Reflex Crit 200I; 14 (3): 469-85.

5. Ribeiro VP, Moura CA. The adverse interactions of the soropositivo mother and the precocious development of the baby. [citado em 2008 Jan 23]. Disponível em: http://agata.ucg.br

6. Polit DF, Beck CT, Hungler BP. Fundamentos de pesquisa em enfermagem: métodos, avaliação e utilização. Porto Alegre: Artmed; 2004.

7. Lopes MV. Validação de software educativo para auxílio ao ensino de sinais vitais [tese]. Fortaleza: Universidade Federal do Ceará; 2005.

8. Schermann LAC. Sensibilidade e aleitamento materno em díades com recém-nascidos de risco. Est Psicol 2005; I0(2): 270-85.

9. Ministério da Saúde (BR). Conselho Nacional de Saúde. Resolução No 196/96. Decreto no 93.933 de janeiro de 1997. Estabelece critérios sobre pesQuisas envolvendo seres humanos. Bioetica 1996; 4(2): 15-25.

10. Galvão, MTG, Paiva, SS. Sentimentos da não amamentação de gestantes e puérperas soropositivas para o HIV. Texto Contexto Enferm 2004; 13(3): 414-9.

11. Instituto Brasileiro de Geografia e Estatística. Estudo especial sobre a mulher. 2008. [citado em 2008 Outy 26]. Disponível em: http://www.ibge.gov.br

12. Ministério da Saúde (BR). Plano Integrado de Enfrentamento à Feminização da Epidemia de Aids e outras DST. Brasília: Ministério da Saúde; 2007.
13. Pinheiro PNC. Mães soropositivas: enfoque educativo visando à melhor Qualidade de vida [dissertação]. Fortaleza: Universidade Federal do Ceará; 2002.

14. Galvão MG. Razões do não uso do preservativo masculino entre pacientes com infecção ou não pelo HIV. I Bras Doenças Sex Transm 200 I; 2(14): 25-30.

15. Silva MR, Bettencourt ARC. Diagnósticos de enfermagem em portadores da Síndrome da Imunodeficiência Adquirida. Rev Bras Enferm 2009; 62(1): 92-9.

16. Maliska ICA. Aids: a experiência da doença e a construção do itinerário terapêutico. Rev Eletrônica Enferm 2007; 9(3): 687-98.

17. Campos RR. Prevalência do papilomavírus humano e seus genótipos em mulheres portadoras e não-portadoras do vírus da imunodeficiência humana. Rev Bras Ginecol Obstet 2005; 27(5): 248-56.

18. Paiva MS. Vivenciando a gravidez e experienciando a soropositividade para o HIV [tese]. São Paulo: Universidade de São Paulo; 2000.

19. Santos NIS. Mulheres HIV positivas, reprodução e sexualidade. Rev Saúde Pública 2002; 36(4): 12-23.

20. Ribas AFP, Moura MLS. Responsividade materna e teoria do apego: uma discussão crítica do papel de estudos transculturais. Psicol Reflex Crít 2004; 17(2): 315-22. 